\title{
Importancia de la mineralogía en la geometalurgia: aplicación en Perú
}

\author{
Importance of mineralogy in geometallurgy: application in Peru
}

\author{
Luis A. Espinoza S.1,a, Guillermo Iriarte D.1,b, Luis O. Espinoza S., ${ }^{1, c}$, Renán Gutarra B., ,d, Melquisedec \\ Herrera M. ${ }^{1, e}$, José Zamalloa B. ${ }^{1, f}$, Vidal S. Aramburú R. ${ }^{2, g}$ Jesus A. Torres G. ${ }^{2, h}$
}

Recibido: 22/10/2020 - Aprobado: 28/06/2021 - Publicado: 23/12/2021

\begin{abstract}
RESUMEN
La contribución de la mineralogía es primordial en las investigaciones mineras modernas. Su importancia radica en la calificación de los yacimientos minerales y en lo que se ha designado como mineralogía de procesos, este concepto ha tomado vigor por las diferentes utilizaciones en el procesamiento de yacimientos minerales. Los estudios mineralógicos facilitan información sobre las diferentes clases de minerales y sus peculiaridades. Con ello se suministra información de la explicación de los resultados obtenidos en las diferentes pruebas metalúrgicas y determinar el potencial que podría afectar al procesamiento. Al ser determinante establecer la disposición de los minerales en el depósito, necesitamos aplicar los distintos métodos de caracterización mineralógica como son la difractometría de rayos $\mathrm{X}$, microscopia electrónica (microsonda y de barrido), microscopia óptica, entre otras. Estos recursos se emplean en forma conjunta, siendo complementarias para obtener la información completa. Esta investigación permite evaluar el rol de la mineralogía en la geometalurgia, los métodos de caracterización; casos aplicados en la lixiviación de Au y flotación de cobre en el ámbito nacional. Se destaca la importancia de la caracterización mineralógica para establecer cuál será el comportamiento metalúrgico de los minerales a procesar.
\end{abstract}

Palabras claves: Geo metalurgia; caracterización mineralógica; microscopia óptica; microscopia electrónica; difractometría de rayos $\mathrm{X}$.

\begin{abstract}
The contribution of mineralogy is essential in modern mining studies. Its importance lies in the qualification of mineral deposits and in what has been designated as process mineralogy, this concept has taken force due to the different uses in the processing of mineral deposits. Mineralogical studies provide information on the different classes of minerals and their peculiarities. This provides information to explain the results obtained in the different metallurgical tests and determine the potential that could affect the processing. As it is decisive to establish the disposition of the minerals in the deposit, we need to apply the different mineralogical characterization methods such as X-ray diffractometry, electron microscopy (microprobe and scanning), optical microscopy, among others. These resources are used together, being complementary to obtain complete information. This research allows to evaluate the role of mineralogy in geometallurgy, characterization methods; cases applied in Au leaching and copper flotation at the national level. The importance of mineralogical characterization is highlighted to establish what will be the metallurgical behavior of the minerals to be processed.
\end{abstract}

Keywords: Geometallurgy; mineralogical characterization; optical microscopy; electron microscopy; X-ray diffractometry.

1 Universidad Nacional Mayor de San Marcos, Facultad de Ingeniería Geológica, Minera, Metalúrgica y Geográfica, E.P. Ingeniería Geológica, Lima, Perú.

2 Universidad Nacional Mayor de San Marcos, Facultad de Ingeniería Geológica, Minera, Metalúrgica y Geográfica, Unidad de Posgrado, Lima, Perú. Docente de Maestría en Geometalúrgia

a Autor para correspondencia: luisomar.espinoza@unmsm.edu.pe - ORCID: https://orcid.org/0000-0002-9568-2627

Email: guillermo.iriarte@unmsm.edu.pe - ORCID: https://orcid.org/0000-0002-8733-4366

c Email: luis.espinoza@unmsm.edu.pe-ORCID: https://orcid.org/0000-0001-5577-8109

Email: renan.gutarra@unmsm.edu.pe - ORCID: https://orcid.org/0000-0002-8374-5416

Email: melquisedec.herrera@unmsm.edu.pe - ORCID: https://orcid.org/0000-0002-4656-0519

Email: jose.zamalloa@unmsm.edu.pe - ORCID: https://orcid.org/0000-0003-4612-073X

Email:varamburur@unmsm.edu.pe - ORCID: https://orcid.org/0000-0001-7411-3866

h Email: jesus.torres5@unmsm.edu.pe -ORCID: https://orcid.org/0000-0001-8186-5249 


\section{INTRODUCCIÓN}

En la geometalurgia los estudios geológicos contribuyen con las relaciones de campo, incluyendo la estructura; los estudios geoquímicos contribuyen con la ley del mineral; la mineralogía contribuye con la cantidad, calidad, modo de ocurrencia, distribución y asociación de las fases minerales de mena y ganga (zonamiento), texturas de la mineralización, y las propiedades físicas; la respuesta metalúrgica define la recuperación; mientras que los estudios geotécnicos son importantes para los objetivos medioambientales y la planificación (Figura 1).

La literatura técnica es abundante en relacionar la importancia de la mineralogía en los procesos metalúrgicos, sin embargo, lo de mayor relevancia es:

- Estudia la disposición de diferentes minerales en un yacimiento y registra la presencia de minerales que puedan ser perjudiciales a los procesos, así como los que generan valor.

- Identifica los cambios mínimos de asociaciones entre partícula valiosa - roca (alteración mineralógica), lo cual puede afectar significativamente la eficiencia y la performance del mineral en la producción de planta.

En la actualidad la tendencia es que la Mineralogía aplicada a la geometalurgia sea capaz de cuantificar los diversos parámetros mineralógicos involucrados para sectorizar las características críticas del depósito definiendo las unidades geometalúrgicas.

\section{MÉTODOS}

La metodología empleada para desarrollar la presente investigación es no experimental del tipo descriptiva ya que ella en función de los objetivos que se persigue nos permitirá hacer el análisis de la numerosa información objeto de estudio, así como nos orientará en las distintas técnicas que se emplean para la recolección de la data, su observación, registro y categorización para su consiguiente interpretación y análisis del marco teórico que a la fecha sustenta la investigación.

\section{RESULTADOS}

\subsection{La mineralogía cuantitativa}

La mineralogía cuantitativa, o mineralogía de procesos, se usa intensivamente para estimar la metodología del proceso, la comprensión de las relaciones que se dan entre mineral valioso y ganga mineral. Los minerales de ganga son componentes mineralógicos altamente importantes al momento de evaluar aspectos críticos como: consumo de energía en los procesos de reducción de tamaño; niveles de recuperación metálica; consumo de reactivos; permeabilidad; entre otros.

Es necesario prestar atención a la ganga al igual que al mismo mineral valioso. Algunos minerales de ganga pueden causar muchos problemas en el proceso como es el caso de la pirita, talco, arcillas, sulfatos, carbonatos y demás.

\subsection{Métodos de caracterización mineralógica}

Los análisis mineralógicos suministran información sobre las especies minerales y sus características. Con ello se facilita interpretar los resultados de las pruebas metalúrgicas y establecer las posibles causas de las dificultades en estos procesos.

Como es necesario definir la composición mineralógica del depósito, se emplean técnicas instrumentales de identificación mineralógica como microscopia óptica,

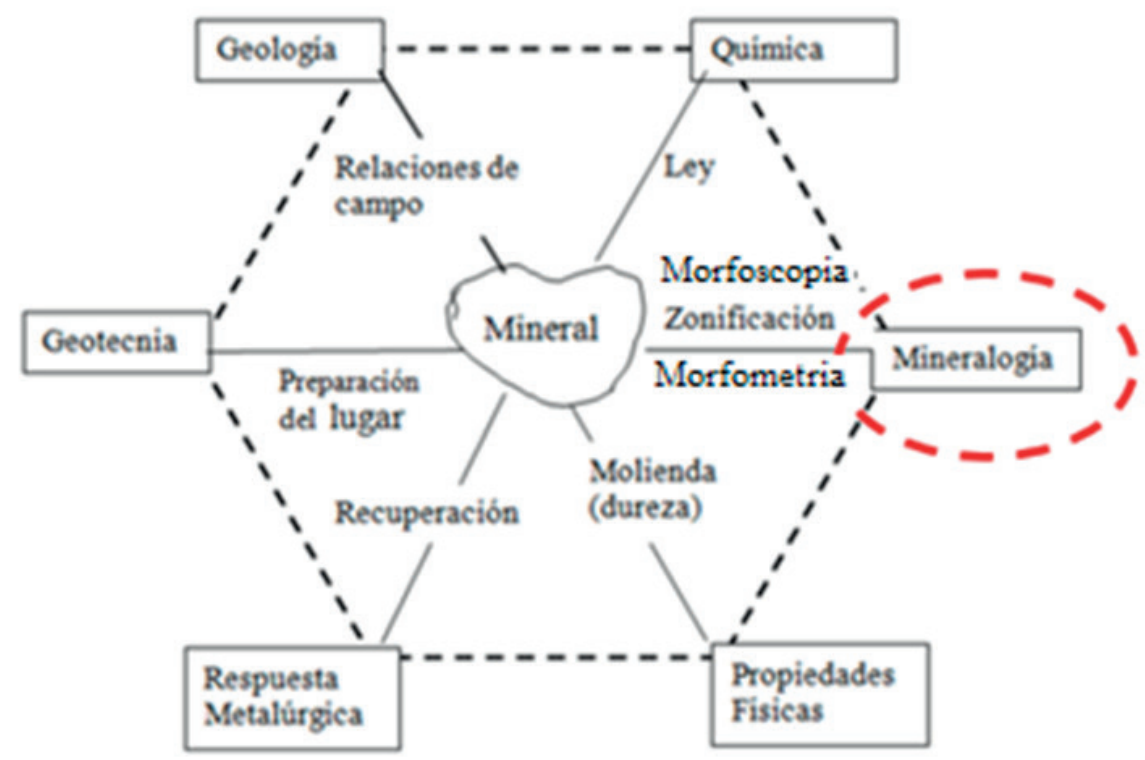

Figura 1. Interconexión de las diferentes asignaturas con la caracterización mineralógica. Fuente: Modificado de (Alfaro, 2015). 
microscopia electrónica (microscopio de barrido/ microsonda) y difractometría de rayos X. Estas técnicas se utilizan en forma conjunta ya que una sola no suministra toda la información necesaria (Figura 2).

\subsection{La mineralogía en el Perú}

La mineralogía es una disciplina de gran aplicación. El Perú puede aprovechar los conocimientos de esta ciencia, para optimizar la extracción, procesamiento y comercialización de los minerales. Para cumplir esta labor resulta imprescindible conocer la mineralogía del yacimiento, además de sus leyes, tonelaje y extensión. De acuerdo con estos factores se puede analizar si el proyecto es rentable o no.

\subsubsection{Aplicación de la mineralogía en la exploración}

La mineralogía sirve como guía para la exploración de minerales, además de dar luces de la composición básica de un yacimiento, como minerales rentables o perjudiciales para el medio ambiente. La enargita y alunita indica la posible existencia de un yacimiento epitermal de alta sulfuración, como las minas de Pierina y Yanacocha. El cuarzo-adularia puede indicar la existencia de un yacimiento epitermal de baja sulfuración, como Orcopampa y Arcata. Un Skarn, como Tintaya, Milpo o Antamina, puede ser identificado con la presencia de epidota, granate, anfiboles y epidota (Guadalupe 2015).
3.3.2. Aplicación de la mineralogía en la explotación del recurso

La explotación de un yacimiento se debe realizar esencialmente en función a los minerales y no solo con las leyes y tonelajes. La mineralogía indicará la mejor forma de procesarlo, como los equipos y reactivos que se utilizarán (Guadalupe 2015).

El valor de un concentrado puede variar de acuerdo con los minerales presentes en el yacimiento, por ejemplo, un mineral de cobre con calcosita presenta hasta $79.8 \%$ de cobre y otro de calcopirita tiene solamente $34.6 \%$. La enargita tiene $48.3 \%$ de cobre, pero debido a la presencia de arsénico $(19.1 \%)$ no podría comercializarse directamente (Tabla 1).

Es importante caracterizar las menas y gangas que se procesarán en las Plantas concentradoras para tomar mejores decisiones al momento de procesarlos.

\subsubsection{Mineralogía en cierre de mina}

Es importante conocer la mineralogía de los relaves, canchas de desmonte, botaderos y todos los materiales asociados al cierre de minas, para minimizar efectos ambientales, como las aguas ácidas. La reactividad química de los depósitos está ligada con la composición de los minerales. Por ello

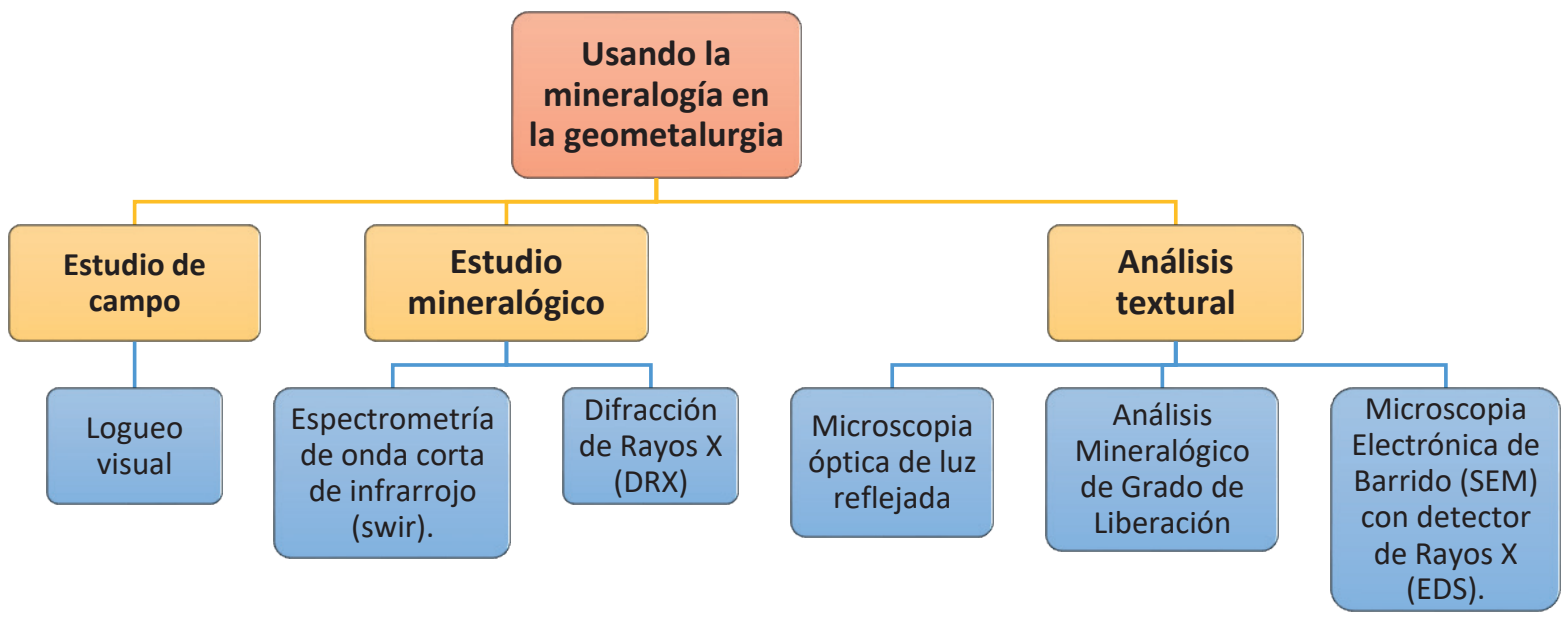

Figura 2. La mineralogía en la geometalurgia: técnicas de caracterización mineralógicas. Fuente: Elaboración propia.

Tabla 1. Mineralogía de algunas menas de cobre

\begin{tabular}{lccc}
\hline Nombre del mineral & Composición química & $\mathrm{Cu} \%$ & Otros elementos \% \\
\hline Calcosita & $\mathrm{Cu}$ & 79.8 & $\mathrm{~S}=20.2$ \\
Calcopirita & $\mathrm{CuFeS}_{2}$ & 34.6 & $\mathrm{Fe}=30.4, \mathrm{~S}=35.0$ \\
Bornita & $\mathrm{Cu} 2 \mathrm{FeS} 3$ & 63.3 & $\mathrm{Fe}=11.2, \mathrm{~S}=25.5$ \\
Enargita & $\mathrm{Cu}_{2} \mathrm{AsFeS}_{4}$ & 48.3 & $\mathrm{As}=19.1, \mathrm{~S}=32.6$ \\
Malaquita & $\mathrm{Cu}_{2} \mathrm{CO}_{3}(\mathrm{OH})_{2}$ & 57.4 & $\mathrm{CuO}=71.9, \mathrm{CO}_{2}=19.9, \mathrm{H}_{2} \mathrm{O}=8.2$ \\
Crisocola & $\mathrm{CuSiO}_{3} \mathrm{nH}_{2} \mathrm{O}$ & 40.4 & $\mathrm{CuO}=32.4-42.2, \mathrm{SiO}_{2}=37.9, \mathrm{H}_{2} \mathrm{O}=12.2-18.8$ \\
Tetraedrita & $\mathrm{Cu}_{12} \mathrm{Sb}_{4} \mathrm{~S}_{13}$ & 45.77 & $\mathrm{Sb}=29.2, \mathrm{~S}=25.0$ \\
\hline
\end{tabular}

Fuente: Guadalupe (2015) 
es necesario estabilizar los materiales para prevenir efectos químicos negativos (Guadalupe 2015).

\subsection{Microanálisis y técnicas de caracterización mineralógica}

\subsubsection{Estudio Mineralógico y textural} (SWIR)

3.4.1.1 Espectrometría infrarroja de onda corta

La espectrometría de reflectancia infrarroja muestra una alta resolución espectral para la aplicación en la determinación de arcillas y otros minerales como carbonatos, sulfatos, sílice, entre otros.

Las muestras no requieren preparación previa, no deben haber absorbido agua del ambiente ya que el agua que no forma parte de los minerales distorsiona los espectros de manera importante (secado a temperatura menor a $60{ }^{\circ} \mathrm{C}$ ). Para aumentar la superficie de reflectividad, sobre todo en el caso de muestras oscuras, las muestras son molidas. La cantidad de muestra requerida es alrededor de $1 \mathrm{~cm}^{3}$. Un equipo muy útil y práctico, basado en la espectroscopia molecular. Se aprovecha los fenómenos de Transmitancia y/o Absorbancia para identificar los más importantes minerales de ganga: Arcillas: kanditas (caolinitas) y esmectitas (montmorillonitas), micas, carbonatos, cloritas, epídotas, alunitas, jarosita, yeso, etc.

\subsubsection{Difracción de Rayos $X(D R X)$}

Esta técnica instrumental para identificar los minerales. Esta técnica se aplica a la aproximación de análisis mineralógicos y va acompañada con análisis elementales por fluorescencia de rayos X (FRX). Los resultados son cualitativos ya que solamente puede determinar relaciones entre los compuestos. Estos resultados se hacen cuantitativos con la ayuda de un software de cuantificación (Londoño, J.I., 2010).

\subsubsection{DRX con tratamiento de etilenglicol} (glicolación):

En el análisis mineralógico de minerales arcillosos por difracción de rayos X (ADRX), se determina la mineralogía global, que incluye la especificación de los minerales de arcillas, presentes en la muestra (BIZALAB Laboratorio,
2020). El proceso de análisis comprende las siguientes evaluaciones:

- Muestra sobre polvo aleatorio.

- Muestra bajo el proceso de separación granulométrica y preparación de muestra orientada (Figura 3).

- Muestra orientada bajo el tratamiento con exposición a vapores orgánicos.

- Muestra orientada bajo el proceso de tratamientos térmicos.

- Mediante este método se realiza la cuantificación de todos los minerales y de las arcillas.

Dispersión de la muestra Filtración al vacío Saturación con etilenglicol

\subsubsection{Microscopia óptica en luz reflejada}

La microscopia óptica permite realizar análisis conocidos (Figura 4); como estudios petrográficos, mineragráficos y petromineragráficos. El microscopio óptico de luz reflejada y transmitida permite identificar distintas clases de minerales, como silicatos, sulfuros, óxidos y otros presentes en una sección delgada pulida (Londoño, J.I., 2010).

Tipos de preparaciones tanto para muestras geológicas y metalúrgicas:

a. Lámina o sección delgada-pulida $(30 \mu \mathrm{m})$ : Estudios petromineragráficos y análisis de grado de liberación. Tipo de Muestras:

- Geológicas de Vetas o cuerpos mineralizados.

- Alimentación, Concentrados o Relaves.

b. Briqueta o Sección Pulida: Estudios mineragráficos, microscopia electrónica, análisis de grado de liberación. Tipo de muestras:

- Geológicas de Vetas o cuerpos mineralizados.

- Alimentación, Concentrados o Relaves.

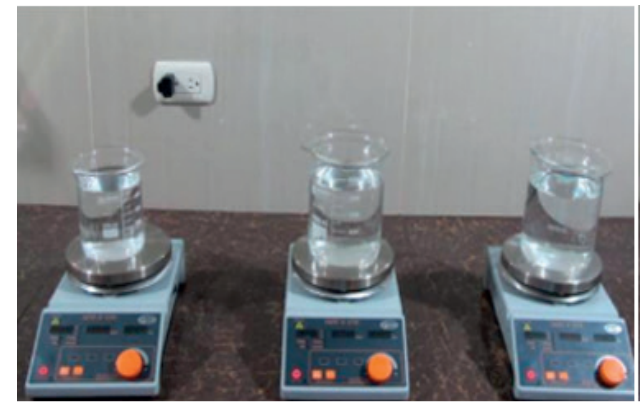

Dispersión de la muestra

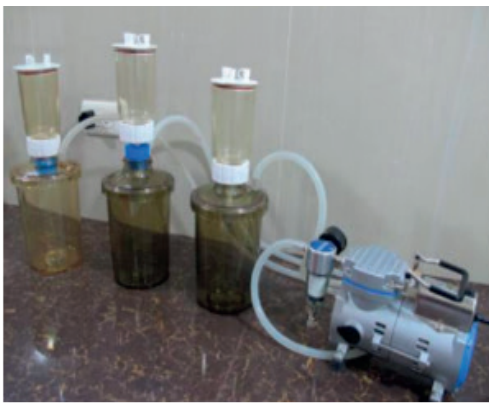

Filtración al vacío

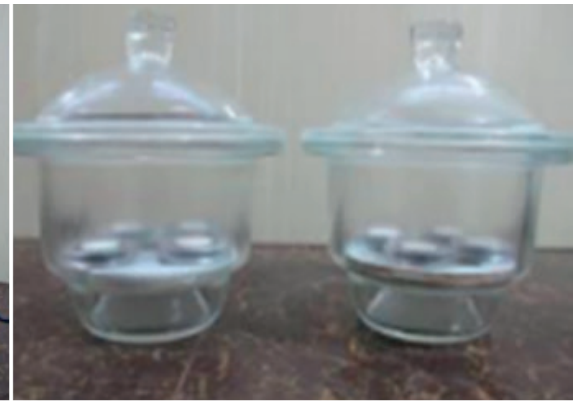

Saturación con etilenglicol

Figura 3. Proceso de análisis con tratamiento de etilenglicol.

Fuente: Elaboracion Propia 


\subsubsection{Microscopia óptica minerales metálicos} (opacos)

Método estándar utilizado para la caracterización de minerales de mena como sulfuros, sulfosales, algunos óxidos, y elementos nativos especialmente metálicos, como el oro.

¿Qué es un mineral opaco y qué propiedades se utilizan para su reconocimiento? Un mineral opaco es aquél cuando la cantidad de luz absorbida es máxima; y la cantidad de luz transmitida es mínima.

Las principales propiedades ópticas que se utilizan en el reconocimiento de minerales opacos son: color, relieve, reflectancia, birreflectancia / pleocroísmo de reflexión, anisotropía, y reflexiones internas. Otra también importante: maclado.

Sus propiedades variarán cuando alguna de las siguientes condiciones sea alterada:

a. Color: Se refiere a la impresión que producen en la vista los rayos de luz reflejada por un mineral opaco/semi-opaco.

- ¿Qué factores interfieren en el reconocimiento de un mineral por su color?

- Calidad de pulido.

- Alteración, debido a la exposición al medio ambiente.

- El desnivel de la sección pulida, Baja reflexión y un color menos definido.
- Asociación del mineral, el mineral varía el color si aparece solo o con otras especies.

a. Reflectancia: Cantidad de brillo que presenta un mineral, es la propiedad que está determinada por impresión subjetiva de la brillantez observada cuando se estudia el mineral.

b. Bireflectancia y/o pleocroísmo: Es la variación en la reflectancia de un mineral en el color cuando la platina del microscopio es girada.

c. Anisotropía: El fenómeno óptico de la anisotropía se produce cuando un mineral no permanece obscuro al girar la platina del microscopio; por el contrario, se observa un cambio de color. Esta propiedad se da cuando el analizador se encuentra insertado (nicoles cruzados).

d. Reflexiones internas: Son aquellos reflejos que provienen debajo de la superficie pulida de un mineral. Se le atribuye como el color real del mineral. Esta propiedad se observa cuando el analizador se encuentra insertado (nicoles cruzados).

e. Maclas: es la asociación regular de cristales de una misma especie que poseen entre si una orientación constante y están relacionados por reglas geométricas. Mediante la observación del microscopio de nicoles cruzados se puede diferenciar fácilmente si un mineral anisótropo presenta macla. Se debe tener presente que si observamos una asociación de minerales diferentes, que no presentan necesariamente una orientación constante se denomina intercrecimiento.

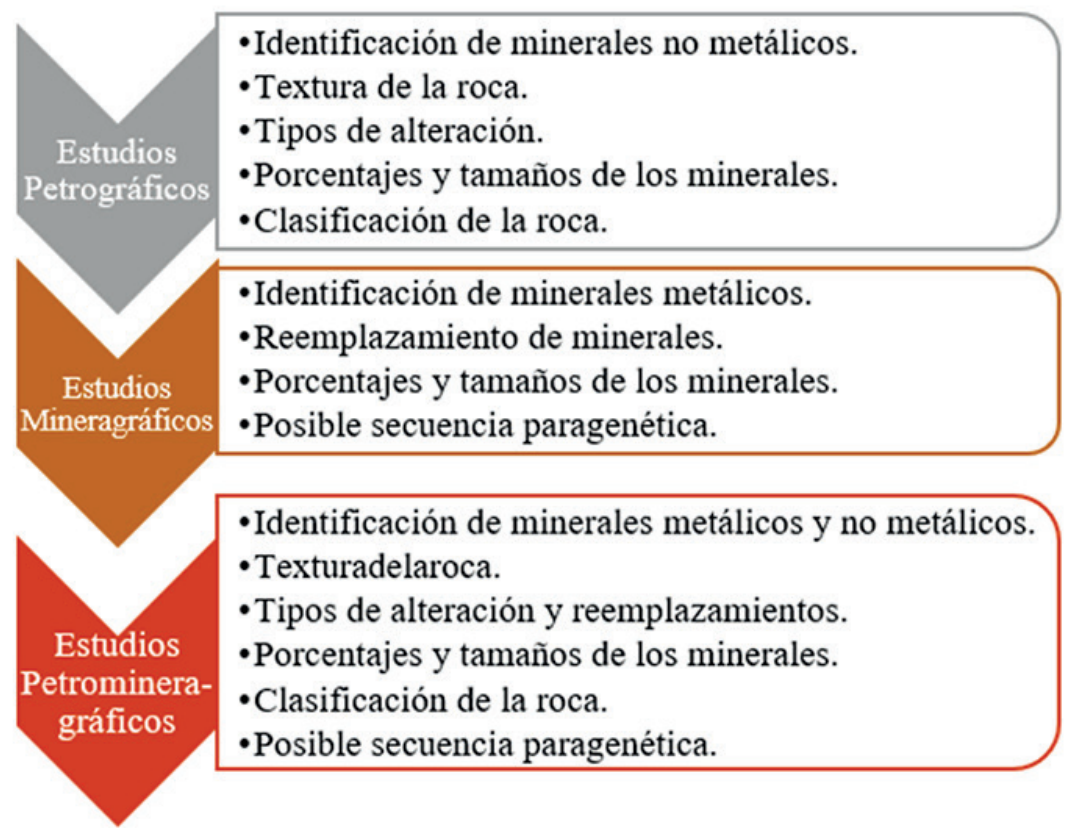

Figura 4. Microscopia óptica y aplicaciones generales.

Fuente: Elaboración propia. 


\subsubsection{Análisis mineralógico de grado de liberación}

Dentro de la información cuantitativa se puede mencionar: tamaños de grano y abundancia relativa de los minerales presentes en la sección de estudio (para muestras de roca). Mención especial es la información proveniente de muestras de procesos metalúrgicos en donde, además de tamaños y abundancia, se obtiene información sobre conteo de partículas (tanto libres como intercrecidos), porcentaje de granos libres e intercrecidos y grado de liberación de las diferentes especies minerales.

Para el cálculo del grado de liberación se utilizó dos factores para la calificación de partículas minerales intercrecidas (Tabla 2)

- El primer factor es el área relativa de cada especie mineral con respecto a un grano mixto (representado en porcentaje en volumen y luego en porcentaje en peso).

- El segundo es considerando la superficie relativa expuesta (dicha zona representa el lugar donde ocurrirá la respuesta metalúrgica). Al multiplicar ambos factores se obtiene el grado de liberación para cada mineral en el grano mixto (BIZALAB Laboratorio, 2020).
La expresión matemática del grado de liberación para una especie mineral por intercrecimientos puede representarse de la siguiente manera:

$$
G L=\sum_{i=0}^{n} \frac{\left(A_{i}\right) m x\left(P_{i}\right) m x}{\left(A_{\text {total }}\right)_{m x}}
$$

\section{Donde:}

$\mathrm{GL}=$ Grado de liberación por intercrecimiento.

$\mathrm{n}=\mathrm{N}^{\circ}$ de partículas

$(A i)_{m x}=$ Área del mineral " $m x$ " en un intercrecimiento.

$(P i)_{m x}=$ Perímetro liberado expuesto del mineral "mx" en un intercrecimiento.

$(\text { Atotal })_{m x}=$ Área relativa total del mineral "mx" en todos los intercrecimientos.

\subsubsection{Microscopia Electrónica de Barrido (SEM)} con detector de Rayos X (EDS)

Es importante tener en cuenta que, para obtener una identificación completa de la mineralogía se requiere

Tabla 2. Arreglos texturales y liberación de partículas

\begin{tabular}{lll}
\hline Descripción & Diagrama & Liberación \\
\hline
\end{tabular}

Ocluido

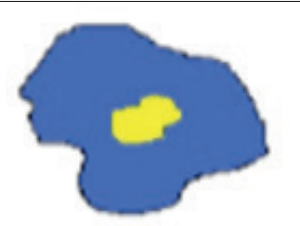

Asociación latera

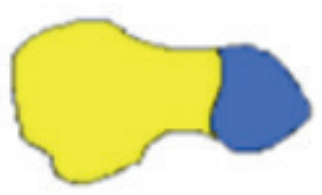

Asociación en donde los minerales aparecen de forma adyacente. Desde un punto de vista metalúrgico, su liberación por vía conminución de ambos minerales es mucho más factible.

Cuando un mineral aparece contenido en otro. A diferencia del tipo diseminado, se observan pocas partículas en el interior del mineral de mayor área. No se forman por exsolución.
Diseminado

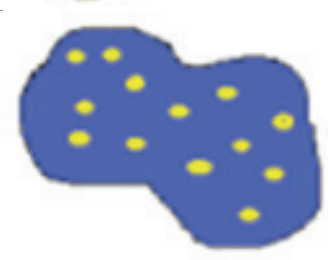
$\because$
Corona

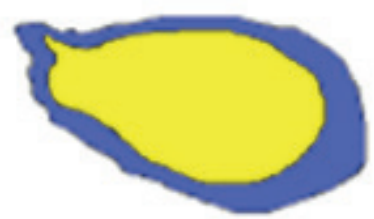

Es una asociación en donde un mineral recubre de manera total a parcial la fase que se encuentra en su interior. La recuperación está supeditada a la naturaleza fisicoquímica del mineral que realiza el "coating" ya que puede pasivar o activar dicho intercrecimiento.

Cuando un mineral aparece en forma de varias y pequeñas inclusiones dentro de otro de mayor fase. La liberación de estas partículas es mucho más compleja lo cual hace de su recuperación prácticamente inviable por procesos de molienda y flotación

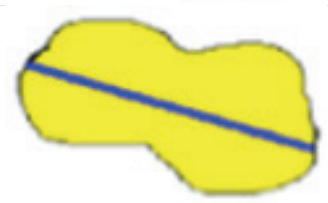

Asociación en donde un mineral aparece "cortado" por una o varias venillas de otro mineral (posterior). La liberación del mineral interior es difícil. 
utilizar, además del microscopio óptico, otras técnicas $\mathrm{y}$ herramientas analíticas como el difractor de rayos $\mathrm{X}$ y el microscopio electrónico de barrido usando detectores adecuados como el EDS, brindando información no solamente cualitativa, sino también semicuantitativa.

\section{A. Fundamentos MEB}

En esta aplicación la información es recogida desde una zona o superficie seleccionada de una muestra, se procesan los datos y luego se genera una imagen 2D. Así se visualiza la variación espacial. Las áreas varían entre $1 \mathrm{~cm}$ y 5 micrones de ancho. La magnificación varía entre $11 x$ hasta aproximadamente 30000x y es capaz de analizar puntos específicos seleccionados por el especialista en la muestra a caracterizar. Este enfoque es útil para la determinación y estudio cualitativo o semicuantitativo de la composición química (utilizando el detector el EDS), complementándose con el detector de electrones retrodispersados.

\section{B. Funcionamiento MEB}

Los electrones acelerados en un equipo SEM tienen una energía cinética significativamente incrementada. Cuantos electrones inciden en la muestra sólida producen una variación en la energía, la disipación de esta energía producirá una variedad de señales (Figura 5).

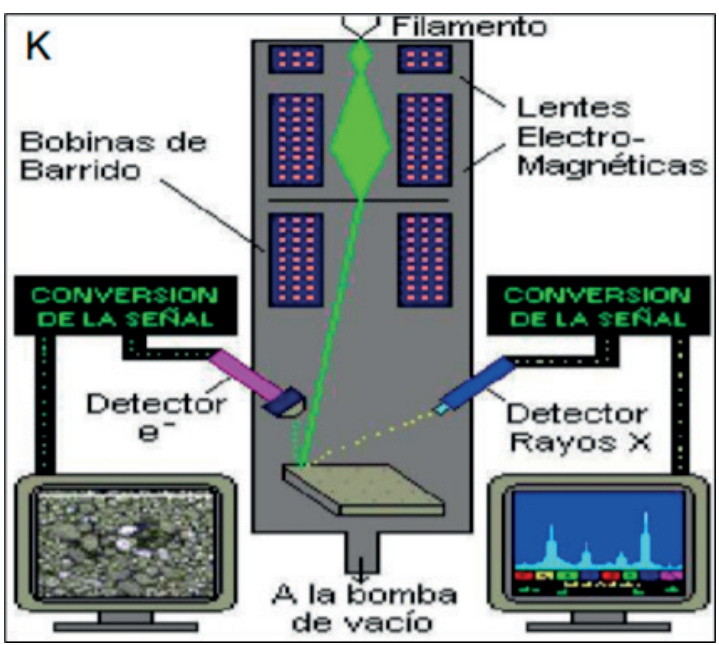

Figura 5. Microscopio electrónico de barrido, sistema de detección de electrones.

Fuente: Universidad de Murcia (2010)

Estas señales incluyen:

- Electrones secundarios (cuales producen las imágenes SEM).

- $\quad$ Electrones retrodispersados (BSE).

- Electrones retrodispersados difractados (EBSD), usados para determinar las estructuras cristalinas y orientaciones de minerales.

- Fotones, con rayos X característicos que serán usados para el análisis elemental.
- $\quad$ Luz visible (para la catodoluminiscencia - CL)

- Calor

a. Electrones secundarios

Los ELECTRONES SECUNDARIOS se producen cuando un electrón incidente excita electrones de la muestra, perdiendo parte de su energía en este proceso. Por convención, son aquellos electrones emitidos por la muestra, con energías menores a $50 \mathrm{eV}$.

La producción de electrones secundarios no varía mucho con la composición de la muestra, sino que depende fuertemente del ángulo entre la superficie y la muestra en el punto de impacto. Por lo tanto, la intensidad de la señal emitida se correlaciona fuertemente con la información topográfica, es decir, con la morfología de la muestra.

b. Electrones retrodispersados

Son electrones primarios que sufren colisiones violentas con los átomos de la muestra, desviando su trayectoria casi sin pérdida de energía, emergiendo desde su superficie; es decir, se retrodispersan ("rebotan"). El BSE puede ser utilizado para una discriminación rápida de fases en una muestra multifásica.

c. Generación de rayos X

Son radiaciones electromagnéticas cuyas longitudes de onda corresponden a la región del espectro electromagnético comprendida entre los $0.01-10 \mathrm{~nm}\left(1 \mathrm{~nm}=10^{-9} \mathrm{~m}\right)$. Los rayos $\mathrm{X}$ se producen por colisiones inelásticas de los electrones incidentes con los electrones que se encuentran ubicados en orbitales discretos de los átomos constituyentes de la muestra en estudio.

Cuando los electrones excitados retornan a niveles energías más bajos, se obtienen los rayos $\mathrm{X}$ con longitudes de onda característicos (relacionado a la diferencia de energía de los electrones que ocurren en los diferentes orbitales para cada elemento dado).

Cada elemento produce rayos $\mathrm{X}$ característicos en un mineral que está "excitado" por el haz de electrones que se incidió en la muestra.

Los análisis SEM son considerados no destructivos y los rayos $\mathrm{X}$ generados por la interacción de electrones no llevan pérdida de volumen en la muestra. Esto permite analizar de manera repetitiva las mismas muestras.

Rayos X: continuos y característicos (background): La mayor parte de los electrones primarios pasan a través del átomo sin interactuar con los electrones orbitales, es decir, no producen rayos- $\mathrm{X}$ característicos (usados para análisis químicos). Los rayos-X emitidos por la muestra 
causan pequeños pulsos eléctricos en un detector en estado sólido. La electrónica asociada (preamplificadores, amplificadores, entre otros.) produce de manera instantánea un espectro; es decir, un histograma de cuentas (número, intensidad) vs la energía de rayos $\mathrm{X}$.

\section{Condición de muestras aptas para MEB}

Generalmente para análisis de muestras relacionados a procesos metalúrgicos se utilizan secciones pulidas. La sección pulida es apta para colocarse en la cámara del microscopio electrónico sin preparación previa si presenta un considerable contenido metálico en su superficie. En ese caso, sólo es necesario colocar cintas de cobre para facilitar detección y visualización en el monitor.

Condición de muestras para grafitador: La grafitación o carbonización de muestras es un método aplicado a la preparación de muestras o especímenes que no presentan propiedades conductoras, de manera que mediante dicha técnica es posible dejar la muestra apta para que se pueda procesar en el microscopio electrónico.

Se puede utilizar de dos formas:

- Utilizando filamentos de fibra de carbón.

- Utilizando una barra de carbón

3.4.1.8 Diferencias entre microscopia óptica y electrónica de barrido

Las principales diferencias encontradas las podemos observar en la Tabla 3:

\subsubsection{Mineralogía automatizada}

Es un sistema automatizado de mineralogía para el análisis cuantitativo rápido de muestras como rocas, minerales, concentrados, residuos, residuos de lixiviación o productos de fundición. Analiza la textura mineral y el grado de liberación. Esta información es invaluable para los geólogos, mineralogistas y metalúrgicos que se dedican a la optimización de procesos, estudios de viabilidad de minas y caracterización de minerales. Software usado en la caracterización en el Perú:

- QEMSCAN: Quantitative Evaluation of Minerals by SCANning electron microscopy.

- MLA SEM: Mineral Liberation Analyzer scanning electron microscope.

- TIMA-X: TESCAN Integrated Mineral Analyser

\subsection{Casos de estudio en el Perú}

Hemos podido observar una serie de ideas y experiencias en el campo de la mineralogía aplicada a la geometalurgia. En la fase de exploraciones y explotación de un yacimiento es necesario la realización de múltiples pruebas de pruebas utilizando el material procedente ya sea de testigos de perforación o de galerías exploratorias. La pruebas que involucran este estudio se deben realizar con un estudio mineralógico garantizando que la mena será tratada de forma óptima.

En el Perú los procesos metalúrgicos de mayor aplicación en el procesamiento de minerales son los procesos de lixiviación (minerales óxidos) y el proceso de flotación (minerales sulfuros).

3.5.1 Mineralogía en procesos de Lixiviación de Au: Caso de estudio La Libertad-Perú

Desarrollo de reportes de microscopía con énfasis en muestras metalúrgicas (Ubero Pascal, 2014).

- Información cuantitativa.

- Cálculo del grado de liberación.

- Descripción de texturas.

Dentro de la información cuantitativa se puede mencionar: tamaños de grano y abundancia relativa de minerales presentes en el estudio. Mención especial es la información proveniente de muestras de procesos

Tabla 3. Principales diferencias entre microscopia óptica y electrónica de barrido

\begin{tabular}{ll}
\hline Microscopia Optica & Microscopia electrónica de barrido \\
\hline la fuente de energía es la luz natural & la fuente de energía es el haz de electrones \\
la imagen se produce por absorciòn de fotones & la formación de la imagen se produce por la dispersión de electrones \\
reproduce imágenes bidimensionales & las imágenes obtenidas son bidimensionales y tridimensionales \\
puede alcanzar un aumento de hasta 1000x & logra aumentos de 200 000x a más \\
bajo poder de resolución & alto poder de resolución \\
identifica a los minerales sobre la base de sus propiedades ópticas & identifica fases según las diversas tonalidades de grises \\
los sensores son los ojos del microscopista & los sensores son los detectores (secundarios y retrodispensados) \\
no cuantifica composición quimica & cuantifica compsición quimica de las fases \\
no identifica ni cuantifica impurezas & identifica y cuantifica impurezas \\
puede direferenciar algunas especies minerales dimorfas & no dieferencia especies minerales dimorfas \\
la muestra requiere ser preparada (sección delgada o pulida) para su estudio & la muestra no necesita que sea preparada, mas si encontrarse seca \\
\hline
\end{tabular}

Fuente: (BIZALAB Laboratorio, 2020) 
metalúrgicos en donde, además de tamaños y abundancia, se obtiene información sobre conteo de partículas, porcentaje de granos libres e intercrecidos y el grado de liberación de especies de minerales (Tabla 4).

La naturaleza de la refractariedad que afecta el proceso de lixiviación es muy variada y a continuación se citarán algunas de sus principales promotores:

- Oclusión o diseminación física.

- Consumo excesivo de cianuro.

- Limitación de oxígeno.

- Materiales carbonáceos
- Revestimiento de las superficies de las partículas de oro.

- Presencia y asociación de menas auríferas con teluro.

En la Figura 7 podemos observar la ocurrencia de oro en una muestra de La Libertad del Perú (formación Chimú).

Es muy importante tener conocimiento a qué mineral o minerales está ligado el elemento de interés además de identificar los posibles problemas que nos pueden traer en el proceso. Es importante realizar el mapeo de estos minerales en el yacimiento y poder advertir en un futuro su ingreso al proceso para poder mitigar su efecto en la operación.

Tabla 4. Resultados del estudio microscópico cualitativo y cuantitativo muestra de La Libertad-Perú

\begin{tabular}{|c|c|c|c|c|}
\hline \multirow{2}{*}{$\begin{array}{c}\text { Minerales } \\
\text { Particulas libres }\end{array}$} & \multirow[t]{2}{*}{$\%$ Vol } & \multicolumn{2}{|c|}{ Partic. Totales } & \multirow{2}{*}{$\begin{array}{l}\text { Observaciones } \\
\text { en agregados granulares de tamaños entre } 300 \text { a } 1000 \text { micras. Muy escasos moldes de } \\
\text { minerales opacos limonitizados-hematizados o venillas de limonitas-hematita }\end{array}$} \\
\hline & & $\%$ Vol & G.L. & \\
\hline $\mathrm{czl}$ & 68.9 & 77.8 & 88.7 & \\
\hline$c z \|$ & 0 & 14.3 & 0 & \\
\hline sil & 0 & 5.9 & 0 & \\
\hline LMs-hm & 0 & 1.3 & 0 & \\
\hline OPs & 0 & 0.7 & 0 & \\
\hline$\sum$ P. Libres & 68.9 & & & \\
\hline \multicolumn{5}{|l|}{ Particulas Mixtas } \\
\hline cz II/LMs-hm & 13.5 & & & $\begin{array}{l}\text { agregados micro a criptogranulares de tamaños }<100 \text { micrones, con moldes de minerales } \\
\text { opacos o playas de limonitas/hematita y moldes lixiviados }\end{array}$ \\
\hline $\mathrm{cz} / / \mathrm{OPs}$ & 7.4 & & & agregados granulares de cuarzo I, con escasas diseminaciones de minerales opacos \\
\hline cz I-cz II & 2.9 & & & $\begin{array}{l}\text { cuarzo I de tamaño }<500 \text { microness, rodeado por cuarzo II. Aparenta textura brechosa. } \\
\text { Escasas playas de limonitas-hematita }\end{array}$ \\
\hline cz l-cz I-sil & 7.3 & & & silice criptocristalina, con fragmentos de cuarzo I y venillas de cuarzo II \\
\hline$\sum$ P. Mixtas & 31.1 & & & \\
\hline Total general & 100 & & & \\
\hline
\end{tabular}

Fuente: Elaboración Propia.

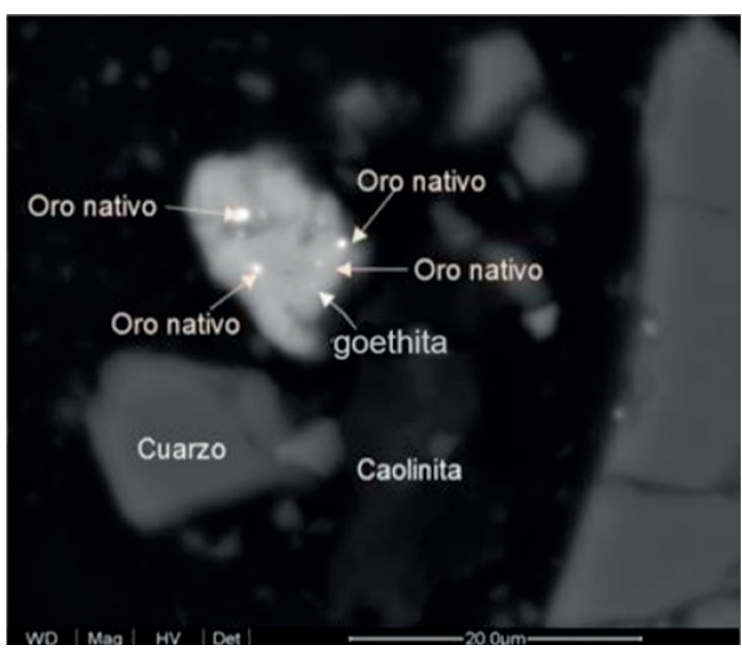

Figura 6. Partículas de oro nativo diseminadas en goethita $(\mathrm{FeO}$

$(\mathrm{OH})$ ), seudomórficas según pirita (aumento 6000x). 


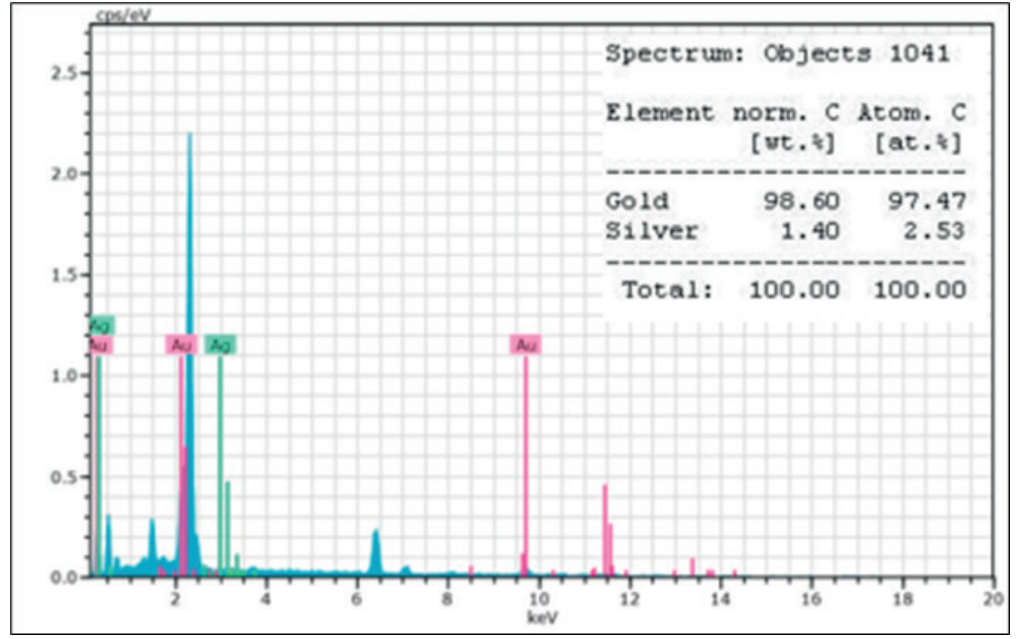

Figura 7. Composición y espectro: Au nativo. Fuente: Elaboración propia.

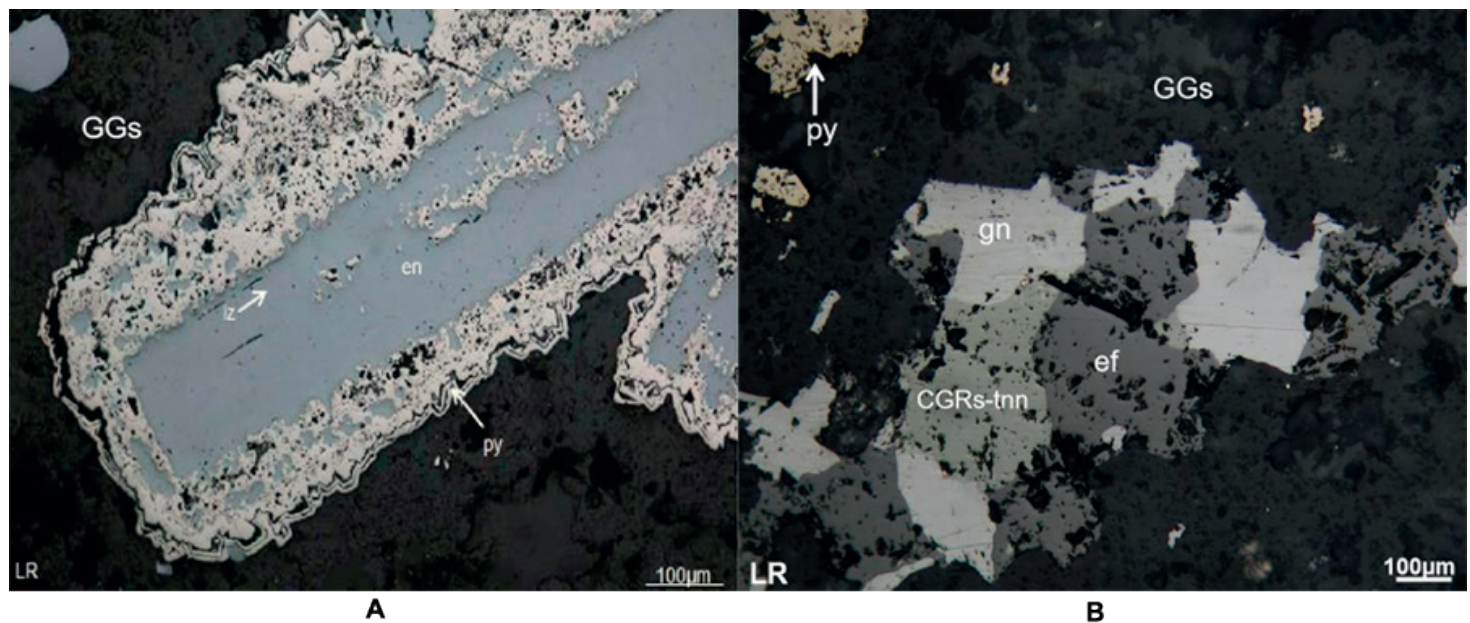

Figura 8. A. Enargita: Agregados de cristales de hábito prismático tabular de enargita (en) reemplazados por pirita (py) desde sus bordes. B. Tenantita: Playas de esfalerita (ef) asociadas con galena (gn) y cobres grises - tenantita (CGRs - tnn). Fuente: Elaboración Propia.

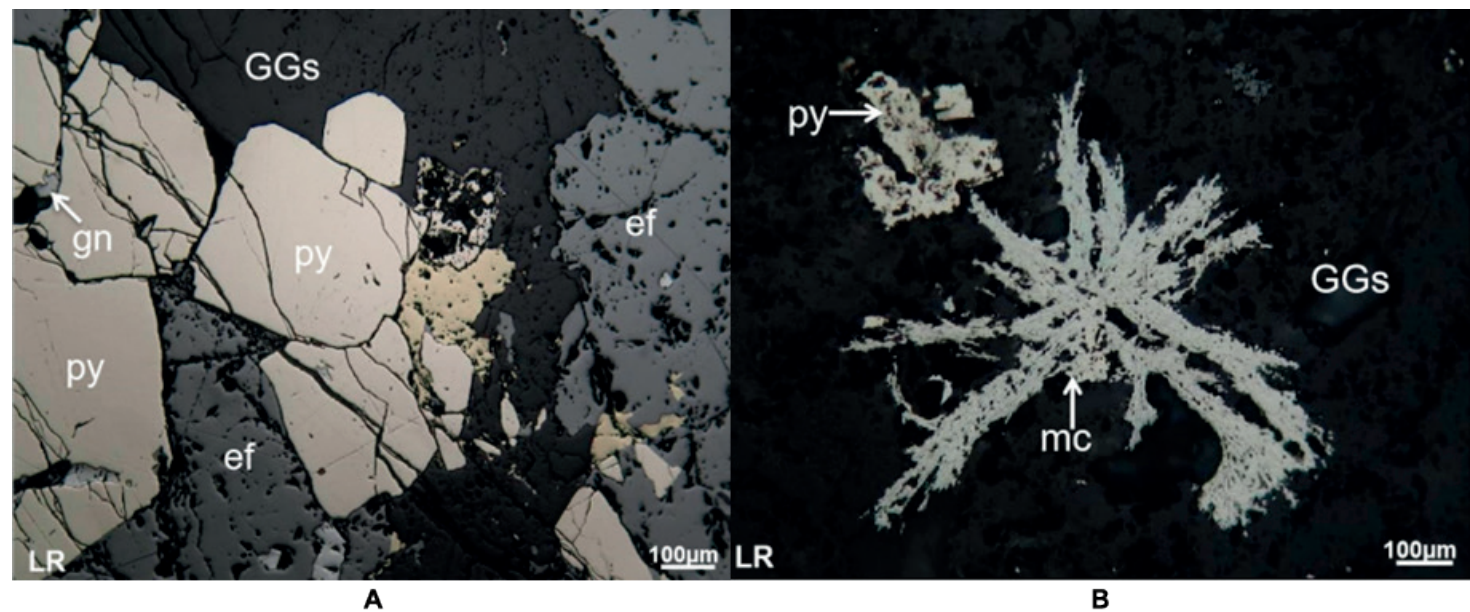

Figura 9. A. Pirita: Agregados de cristales de hábito cúbico de pirita (py) ocluidos en gangas (GGs) y bordes e intersticios ocupados por playas de calcopirita (cp), esfalerita (ef) y galena (gn). B. Marcasita: Agregados de cristales de hábito prismático de marcasita (mc) y pirita (py) ocluidos en gangas (GGs). Fuente: Elaboración Propia. 
La caracterización de gangas y su cuantificación es de mucha utilidad en procesos de lixiviación en pilas (Figura 10).

3.5.2 Mineralogía en procesos de flotación caso de estudio: minerales del distrito minero de Tintaya, Espinar - Cusco

Caracterización mineralógica con un enfoque geometalúrgico en cuatro muestras, tres en intrusivos y uno en skarn de magnetita del yacimiento pórfido-skarn del Batolito Andahuaylas-Yauri.

Esta importante unidad está conformada por pulsos magmáticos del batolito Andahuaylas-Yauri y ha sido producto de varios eventos magmáticos ocurridos entre el Eoceno y Oligoceno. Las diferentes fases de intrusión se caracterizan por presentar composición, textura, tamaño de grano y formas de emplazamiento muy variables.

Las principales actividades que se desarrolla para este tipo de muestras son las siguientes:
- Logueo de taladros diamantino en sala.

- Análisis de pruebas metalúrgicas: ensayo químico ( $\mathrm{Cu}$ Secuencial), test de caída en peso JKDWT, Work Index (Índice de trabajo), pruebas de flotación (recuperación).

- Estudio de espectrometría.

- Estudio de estereoscopia en core, para la identificación mineralógica macroscópica.

- Estudio petromineragráfico de secciones delgadas-pulidas.

- $\quad$ Estudio de difracción de rayos X (DRX)

\subsubsection{Análisis de cobre secuencial}

Finalidad de determinar el tipo de mineral de cobre presente en las muestras (ver Figuras 11,12 y 13)

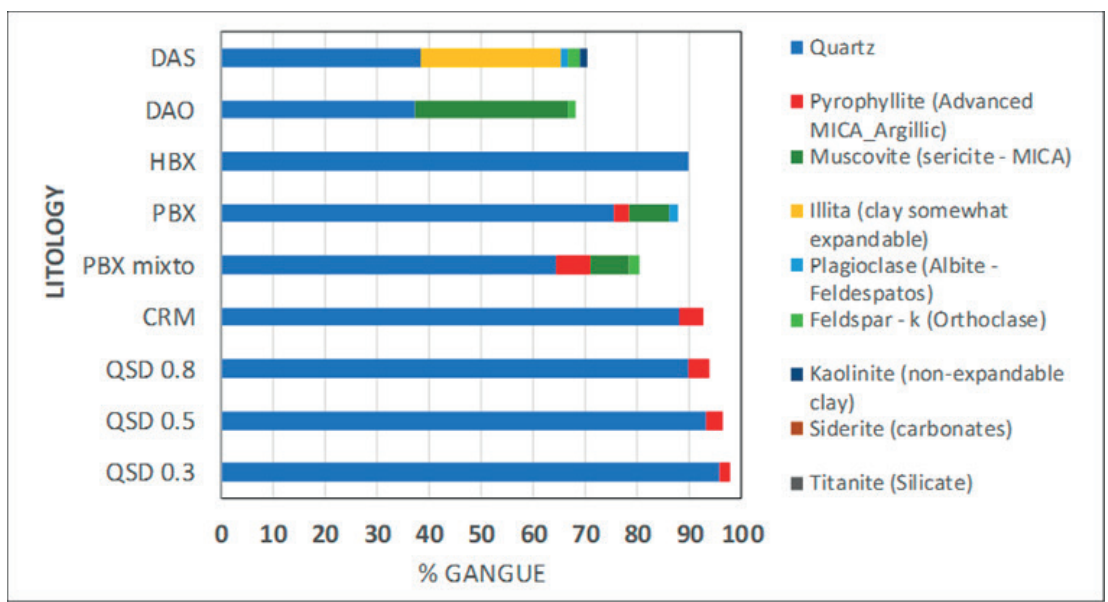

Figura 10. Caracterización de gangas.

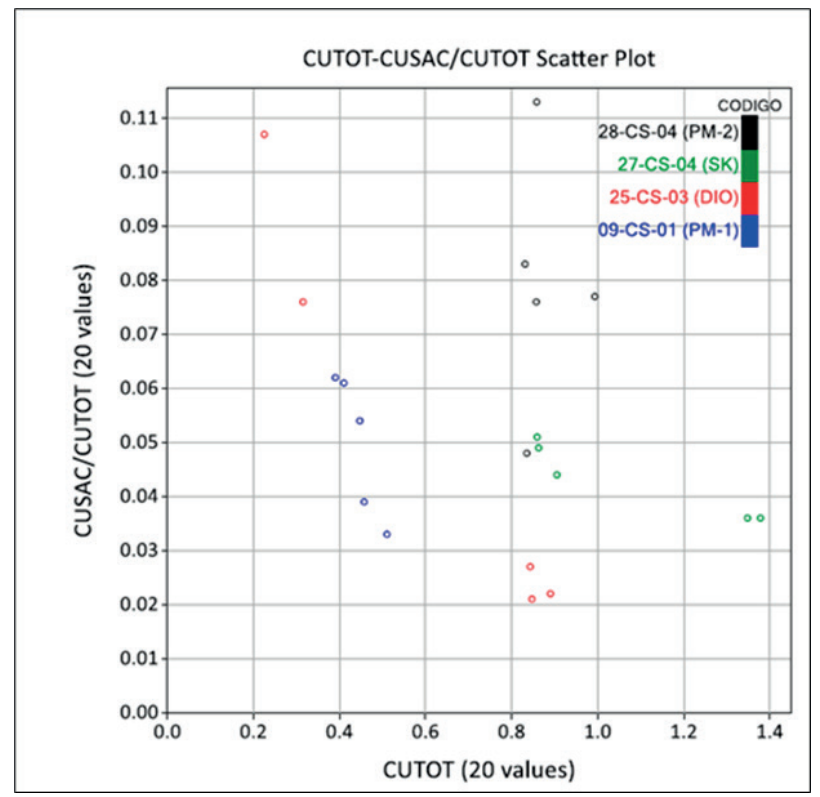

Figura 11. Resultados del ratio CUSAC/CUTOT, son menores del $11 \%$ esto indica minerales oxidados de $\mathrm{Cu}$. Fuente: (NINA VILCA, 2019) 


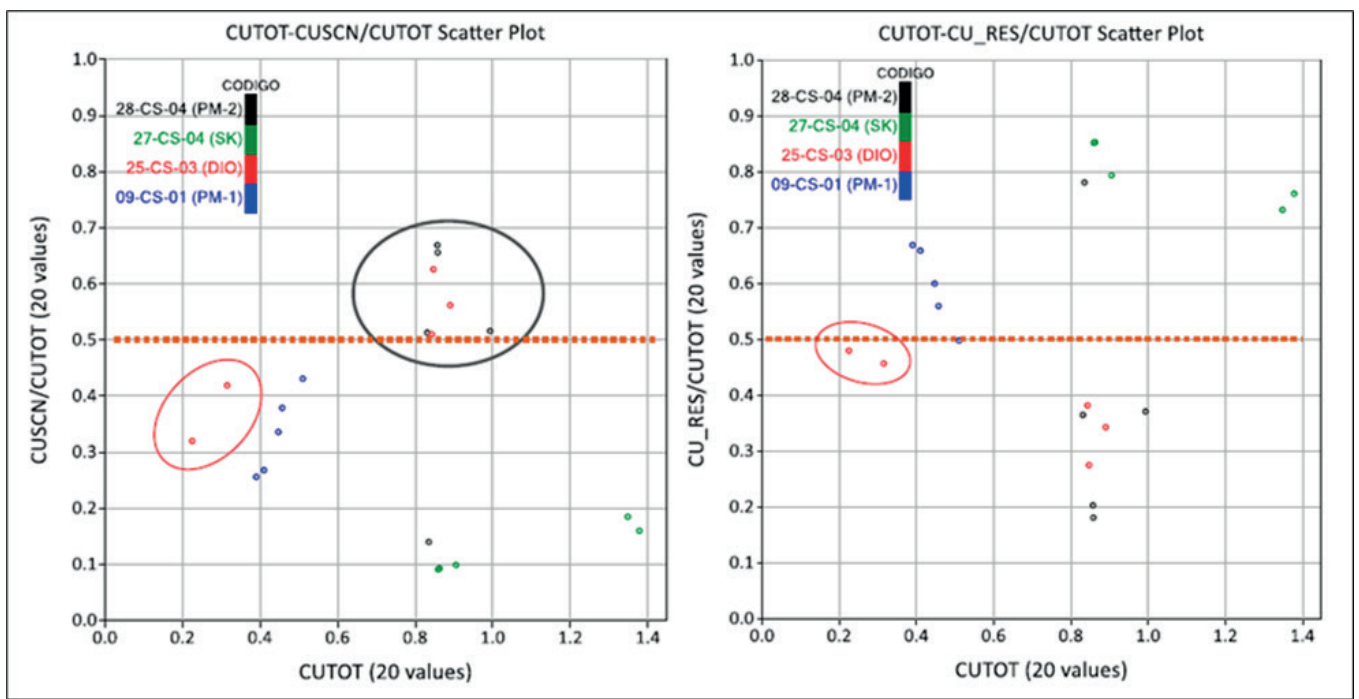

Figura 12. Resultados del ratio CUSCN/CUTOT, el cual identifica minerales secundarios de cobre, cobre residual son variables y van desde $20 \%$ hasta $85 \%$ indicando esto que la distribución de la calcopirita es muy variable. Fuente. (NINA VILCA, 2019)

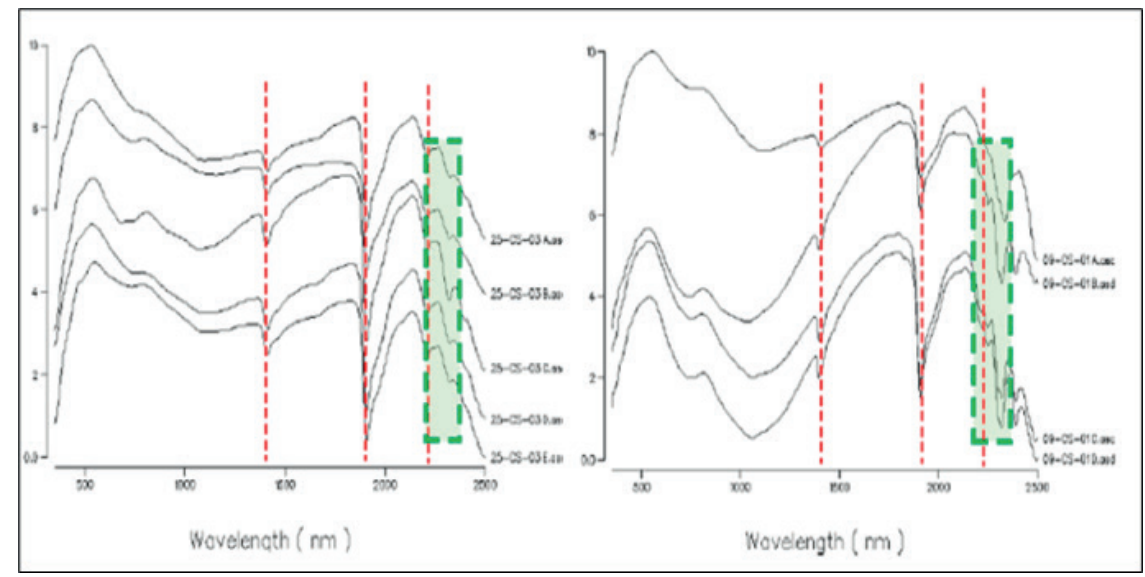

Figura 13. Resultados espectros obtenidos de las muestras del estudio remarcando en rojo las absorciones de la montmorillonita y en verde absorciones del grupo de las cloritas Fuente: (NINA VILCA, 2019)

El cuerpo intrusivo pre-mineral Monzodiorita (DIO), presenta alteración incipiente con carbonatos moderados, con ley de $0.87 \%$ de Cu. (ver Figuras 14 y 15 ).

\subsubsection{Mineralogía en procesos de flotación caso de} estudio: Gold Fields (Cerro Corona)

El pórfido cuprífero Cerro Corona desarrollado en la región Cajamarca, produce concentrados de cobre con contenidos de oro, mediante explotación de tajo abierto por tratamiento de procesos de flotación para concentrar los minerales sulfurados.

La mineralogía modal (cuantitativa) fue determinada, así como la ocurrencia del mineral predominante de cobre, la calcopirita. Este fue caracterizado mediante análisis de Qemscan, y reportando resultados incluyendo el tamaño de grano, la liberación y las asociaciones.

$\underline{\text { Resultados mineralogía cualitativa (ver Figura 16) }}$

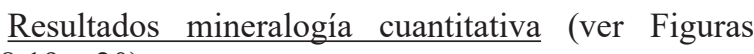
$17,18,19$ y 20$)$.

\section{DISCUSIÓN}

A partir de los casos de estudio se puede observar como la mineralogía ha sido un factor integrador desde la implementación de conceptos geometalúrgicos en la industria minera hace casi dos décadas y ante la situación actual de la industria de minerales es hora de volver a examinar su papel en términos de uso rutinario de la planta, herramienta de I + D y contenidos de la docencia universitaria. La aplicación y uso de herramientas como son: analizadores de minerales automatizados, difracción de rayos X con modelado semicuantitativo por el método Rietveld, espectrometría infrarroja para la identificación y caracterización de materiales complejos, entre otros, están permitiendo la extracción eficiente y sostenible en la industria minera. 


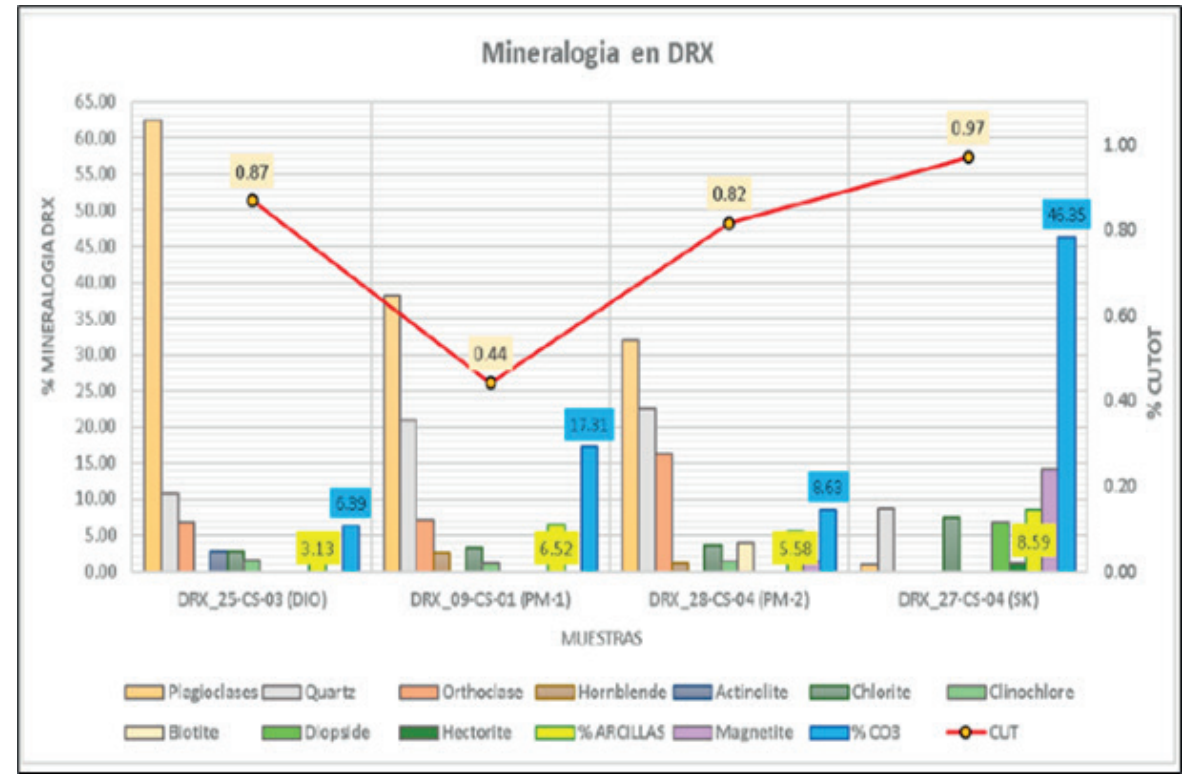

Figura 14. Porcentajes de las fases minerales identificados en DRX por cada muestra analizada. Fuente. (NINA VILCA, 2019)

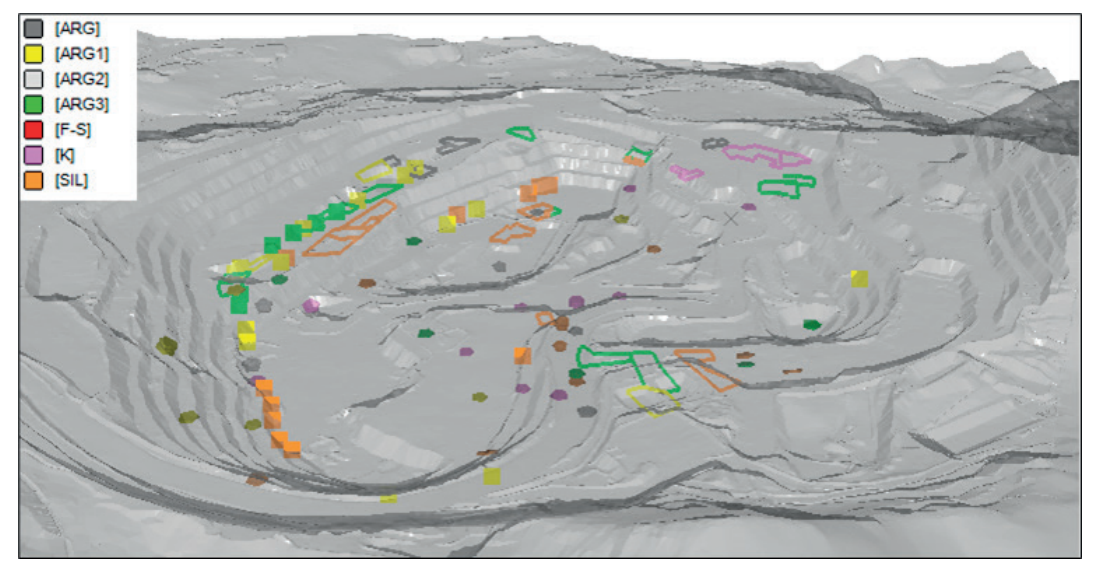

Figura 15. Ubicación espacial de muestras y clasificación por alteración (Logueo).

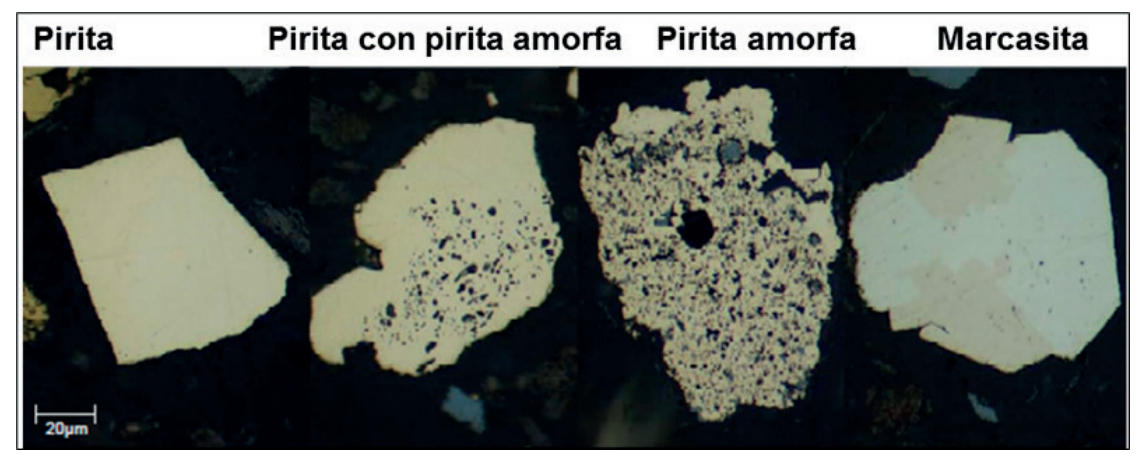

Figura 16. Ocurrencia de los tipos de pirita, así como marcasita.

Fuente:(Baumgartner et al., 2016)

Los estudios mineralógicos detallados tendrán como misión garantizar el conocimiento integral de la mena para tener la seguridad que el yacimiento se explotará racionalmente. Un mineralogista experimentado recomendará, sobre bases geológicas, poner atención a otros elementos que podrían encontrarse en el yacimiento y consecuentemente aumentar el valor del mismo.
Los estudios mineralógicos establecen el grado entre las leyes del metal de interés contenido en las menas del depósito. Teniendo en consideración las leyes de cabeza se podrá realizar pruebas experimentales, en las que se debe realizar trabajo de control mineralógico.

Toda técnica es capaz de identificar las propiedades físicas o químicas de los minerales a escala macro-, micro-, 


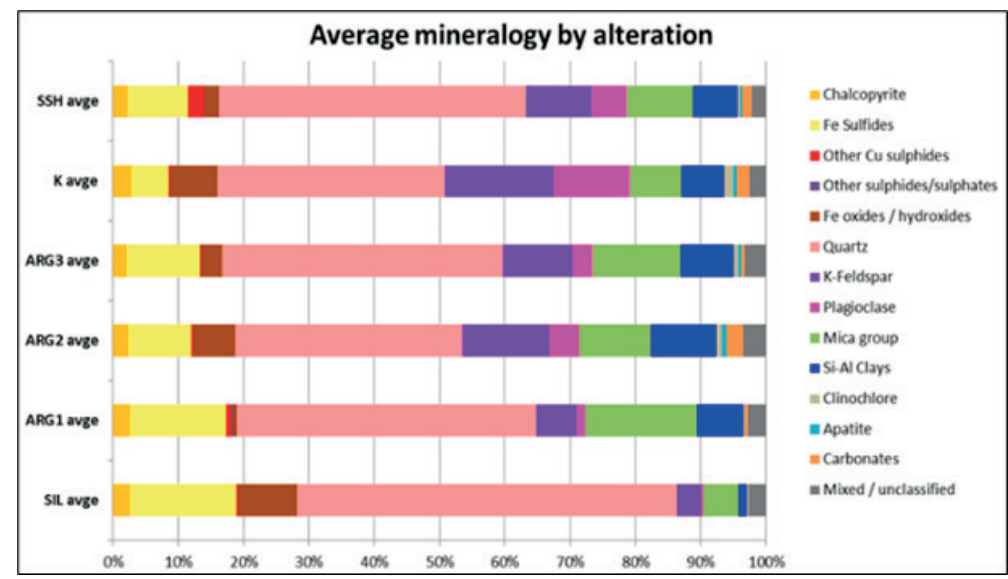

Figura 17. Mineralogía modal promedia por cada tipo de alteración

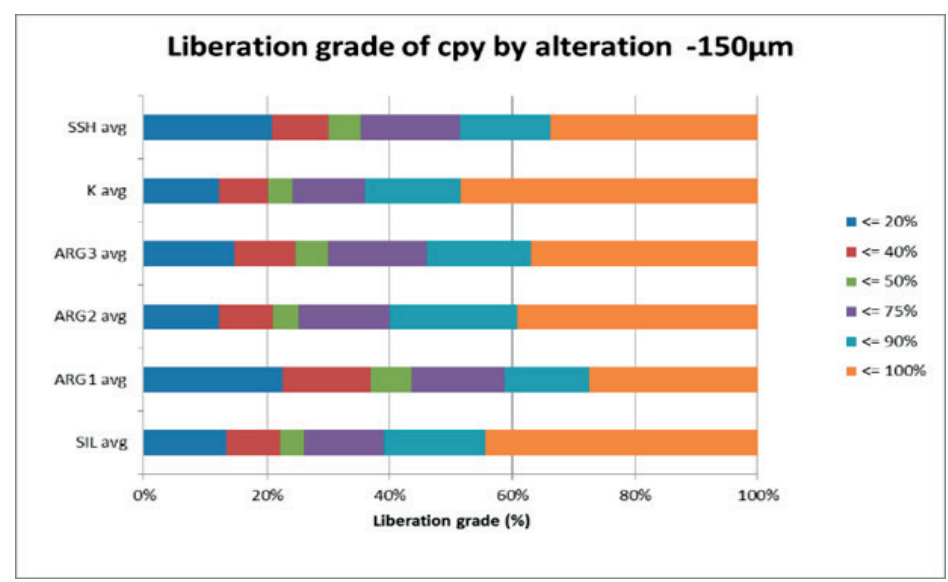

Figura 18. Liberación de calcopirita de $150 \mu m$ según las diferentes alteraciones

\begin{tabular}{|c|c|c|c|c|}
\hline Tipo & $\begin{array}{l}\text { Micro-estructuras } \\
\text { tipicas }\end{array}$ & Descripción & Ejemplos en Cerro Corona & $\begin{array}{l}\text { Ocurrencia y } \\
\text { solución de } \\
\text { extracción }\end{array}$ \\
\hline $1 \mathrm{a}$ & & $\begin{array}{l}\text { Inter-crecimiento } \\
\text { simple o tipo } \\
\text { encapsulado. } \\
\text { Rectilineoo } \\
\text { limites } \\
\text { ligeramente } \\
\text { curvos } \\
\text { - Tipo más común }\end{array}$ & & $\begin{array}{l}\text { Abundante } \\
\text { Molienda más fina. }\end{array}$ \\
\hline $1 b$ & 8 & $\begin{array}{l}\text { Inter- } \\
\text { crecimientoso } \\
\text { encapsulamiento } \\
\text { tipo moteado, } \\
\text { manchado, tipo } \\
\text { ameba } \\
\text { - Patrón común } \\
\text { simple }\end{array}$ & & $\begin{array}{l}\text { Abundante } \\
\text { No solución directa, } \\
\text { puede flotar si } \\
\text { calcopirita está } \\
\text { asociada a pirita. Si } \\
\text { asociado con ganga, } \\
\text { será deprimido. }\end{array}$ \\
\hline $2 a$ & & $\begin{array}{l}\text { Recubierto, } \\
\text { envuelto, o tipo } \\
\text { corona, borde, } \\
\text { anular, o atolón. }\end{array}$ & & $\begin{array}{l}\text { Escaso } \\
\text { Molienda más fína }\end{array}$ \\
\hline 3a & & $\begin{array}{l}\text { Tipo veta, tipo } \\
\text { "stinger". } \\
\text { Ejemplos } \\
\text { comunes }\end{array}$ & & $\begin{array}{l}\text { Escaso } \\
\text { Molienda más fína } \\
\text { para aumentar la } \\
\text { liberación. }\end{array}$ \\
\hline
\end{tabular}

Figura 19. Ejemplos de texturas en Cerro Corona que podrían impactar en el proceso. Fuente: (Baumgartner et al., 2016) 


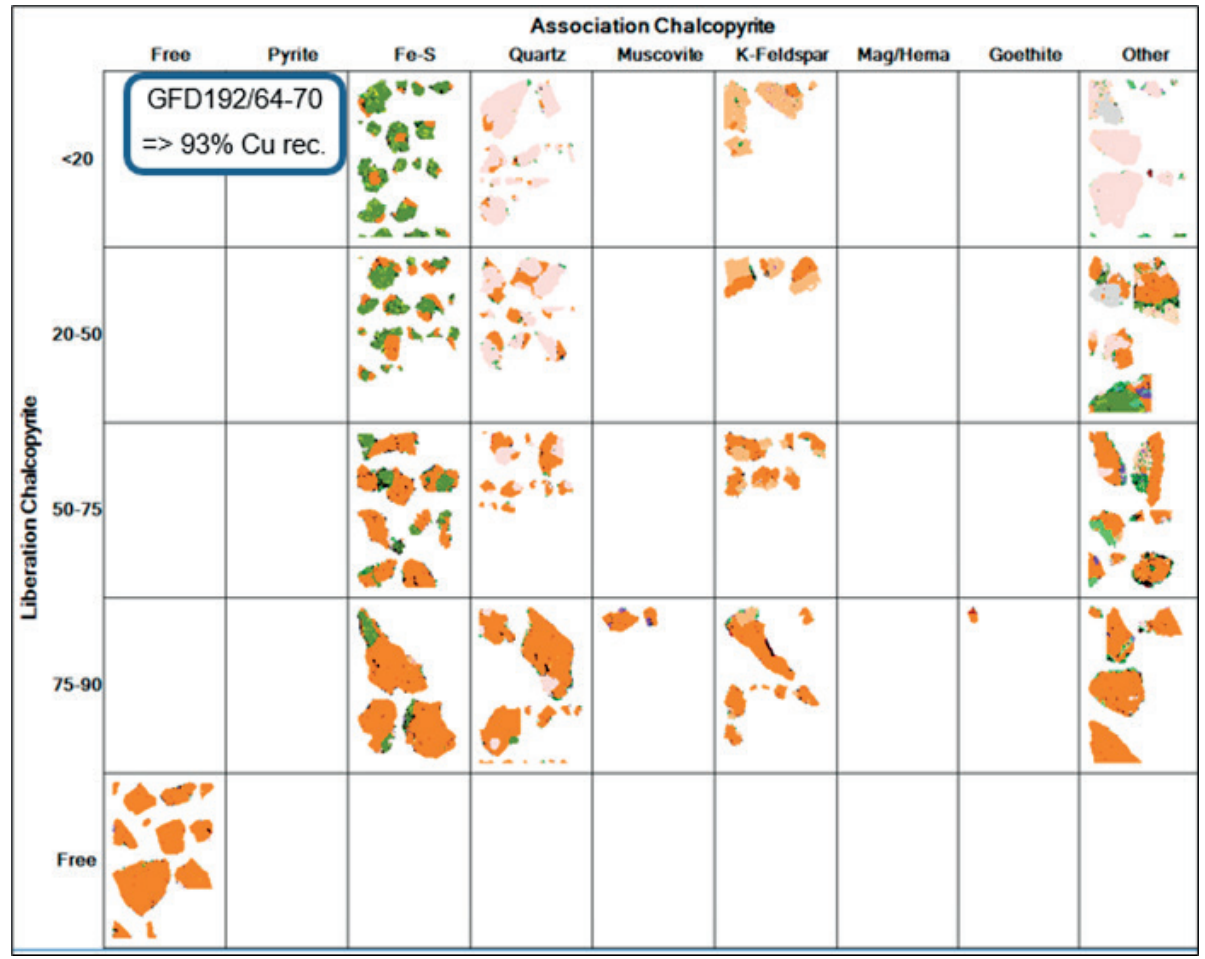

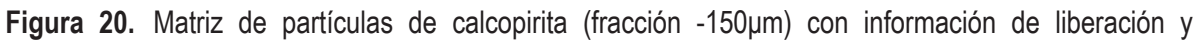
asociaciones de la muestra.

Fuente: (Baumgartner et al., 2016)

o nanoscópica se presentará un interés real por el desarrollo de mineralogía analítica aplicada, que se complemente de forma eficiente con el desarrollo de técnicas de caracterización Existe un gran número de métodos que nos permiten caracterizar las propiedades de la materia. Los datos generados a partir de estos estudios ayudan a describir la mineralogía y el comportamiento (textura) de las diversas fases de minerales en la mena para optimizar la recuperación y la selectividad de lo minerales que se tienen en campo.

\section{CONCLUSIONES}

- La Mineralogía de Procesos nos permite inducir la respuesta metalúrgica de los materiales de los minerales que se tienen en el depósito para procesar. La geometalurgia utiliza la Mineralogía de Procesos para mejorar los diagramas de flujo del tratamiento de minerales tal como se pudo observar en los casos de estudios.

- La información obtenida a partir de los estudios de caracterización mineralógica y comportamiento (textura) de las fases de minerales en menas de interés permiten optimizar la producción y nos brinda las herramientas para ser selectivos ya que nos permite identificar minerales que son perjuiciosos al proceso, permite predecir también los impactos medioambientales.

- La caracterización mineralógica durante el proceso permite no solamente justificar bajas extracciones en el proceso de beneficio sino también monitorear la producción en planta.

- Conocer los minerales portadores del elemento de interés es fundamental y parece lógico, pero no lo es para todos. Para eso, hay que utilizar diferentes técnicas analíticas.

\section{AGRADECIMENTOS}

Los integrantes de este equipo de investigación agradecemos cordialmente al Instituto de Investigación de la Facultad de Geología, Minas, Metalurgia y Ciencias Geográfica de la Universidad Nacional Mayor de San Marcos; a la vez hacemos extensivo nuestras muestras de afecto y gratitud a nuestro docente Jesús Alberto Torres Guerra por transmitir su pasión por la ciencia e incentivarnos para la publicación de este artículo de investigación.

\section{REFERENCIAS}

Alfaro, E. (2015). La Geometalurgia: prospectiva en minería y formación academica de especialistas. Pontificia Universidad Católica Del Perú- Sección Minas, Área - Metalurgia, 2-8.,1-10. https://www.academia.edu/12165176/ LA_GEOMETALURGIA_PROSOPECTIVA_EN_ MINERIA_Y_FORMACIÓN_ACADEMICA_DE_ ESPECIALISTA $\bar{A} S ?$ auto $=$ download

Baumgartner, R., Escobar, G., Gomez, P., Uzategui, A., \& Nuñez, F. (2016). Caracterización mineralógica detallada en el depósito de $\mathrm{Cu}-\mathrm{Au}$ Cerro Corona - La clave fundamental 
para la geometalúrgia y la optimización de procesos. XVIII Congreso Peruano de Geología, p. Xxx-Xxx (2016), 1-4. https://app.ingemmet.gob.pe/biblioteca/pdf/CPG18-70.pdf

BIZALAB Laboratorio. (2020). Laboratorio para análisis mineralógicos con la técnica de Difracción de Rayos $X \quad(D R X)$. https://www.facebook.com/BIZALAB/ photos/a.1256532634453236/3083090271797454/

Cedillo-P., E. (1979). Control mineralógico de procesos metalúrgicos: aplicación de la microscopía de luz reflejada. In Minero Perú (pp. 26-37). https://sisbib.unmsm.edu.pe/ bibvirtualdata/publicaciones/ing geologo/n17_1980/a02. pdf

Guadalupe, E. (2015). La mineralogía en el negocio minero metálico. Revista Del Instituto de Investigación de La Facultad de Ingeniería Geológica, Minera, Metalurgica y Geográfica, 18(35). https://doi.org/https://doi.org/10.15381/ iigeo.v18i35.11852

Londoño, J.I. (2010). Técnicas mineralógicas, químicas y metalúrgicas para la caracterización de menas auríferas. In Ingeominas. Ministerio de Minas y Energía, Colomiba. https://doi.org/10.32685/9789589789667
Melgarejo, J. C., Proenza, J. A., Galí, S., \& Llovet, X. (2010). Técnicas de caracterización mineral y su aplicación en exploración y explotación minera. Boletin de La Sociedad Geologica Mexicana, 62(1), 1-23. https://doi.org/10.18268/ BSGM2010v62n1a1

NINA VILCA, W. R. (2019). CARACTERIZACIÓN MINERALÓGICA E IMPLICANCIAS GEOMETALÚRGICAS EN EL YACIMIENTO PÓRFIDOSKARN DEL BATOLITO ANDAHUAYLAS-YAURI [Universidad Nacional de San Agustín de Arequipa]. In CARACTERIZACIÓN MINERALÓGICA E IMPLICANCIAS GEOMETALÚRGICAS EN EL YACIMIENTO PÓRFIDOSKARN DEL BATOLITO ANDAHUAYLAS-YAURI. http:// repositorio.unsa.edu.pe/handle/UNSA/8696

Ubero Pascal, N. (2014). Guía Docente Técnicas de Microscopía aplicada a las Ciencias Forenses. Universidad de Murcia. Máster Ciencias Forenses, January 2010, 1-12. https://www. um.es/innova/OCW/Microscopía-aplicada-a-las-cienciasforenses/microscopia/material_clase/presentacion_4.pdf 